\title{
Evaluation of the customer value of component redundancy in electrical distribution systems
}

\author{
Lina Bertling, Member IEEE, Mats B-O Larsson, Member IEEE, and Carl Johan Wallnerström
}

\begin{abstract}
A new regulatory model for the Swedish electrical distribution system operators has been proposed, and is now being implemented. The model is referred to as the Network Performance Assessment Model (NPAM). The NPAM is based on fictive reference networks. These emanate from a radial network that is reinforced with redundant components if it increases the customer value more than required investment cost for higher system reliability. The NPAM involves a paradigm shift for the Swedish DSO from a system based on compensation for costs to one based on performance. Evidently, it is of great importance to both the regulator and the different DSOs to evaluate how well the NPAM calculates the performance i.e. the customer values. The aim for this paper is to take a first step in this process; by putting light on how these redundant reference networks are created and used for the NPAM. In order to do this a comparative study has been made for a small test system where two different approaches are used for identifying the resulting redundant reference network for a system. The NPAM approach uses a Monte Carlo simulation technique, and the comparative approach uses an analytical based reliability assessment tool RADPOW, developed at KTH.
\end{abstract}

Index Terms-Customer value, Electrical distribution systems, Network Performance Assessment Model, Outage cost, Power systems, Probability, Performance based regulation, Redundancy, Reference networks and Reliability.

\section{INTRODUCTION}

Ear ectrical energy customers generally require high availability in the power supply. However, if, as for other goods, the customer were to pay a price for electricity corresponding to the customer value, different customers, such as industrial or household, would have different values for energy not supplied Consequently, there would be different set of prices for power supply from a customer point of view. From the perspective of the electrical distribution system operator (DSO), there is a cost for operation and maintenance of the electrical distribution system, to balance against the requirements for system reliability and the profit for the stakeholders. In a perfect market environment, a balance would be reached where customers select the DSO with the best price for the required customer value. However, the infrastructure for the electrical distribution system is in most cases still under a monopoly. To manage this situation the authorities apply different regulatory tools. In Sweden, a

This work has partly been supported by the Competence Centre in Electric Power Engineering (EKC) at KTH.

L. Bertling (e-mail: lina.bertling@ets.kth.se) and C. J. Wallnerström (email: cjw@kth.se) are with the Royal Institute of Technology (KTH) in Stockholm, Sweden

M. B- O Larsson is with MML, Åhus, Sweden. regulatory tool is being introduced by the Swedish energy agency (STEM), referred to as the Network Performance Assessment Model (NPAM) [1]- [4].

The NPAM aims to regulate the network tariffs, i.e. the price that the DSO charges the power supply customers, based on the customer value. An increase in network tariffs should then only be valid if it creates higher customer value, e.g. by increased system reliability. It is important to realize, however, that an increase in system reliability does not necessarily lead to a corresponding increase in customer value. The increase in customer value might be lower than the cost of increasing the reliability and the DSO will not be completely compensated by the network tariffs. Another purpose of the NPAM is to compare tariffs between different DSO depending on their electrical distribution system and corresponding customer value.

The NPAM is based on reference networks. A reference network is a fictive electrical distribution system that is defined from a set of objective prerequisites such as location of customers. Moreover, the reference networks emanate from a radial network that has been reinforced with redundant components e.g. feeders in parallel. The principle when creating the redundancy for the reference networks was that the investments for improving the system reliability are motivated only if this increases the customer value more than the required cost for higher reliability.

The ongoing introduction of NPAM involves a paradigm shift for the Swedish DSO from a system based on compensation for costs to one based on performance. Evidently, it is of great importance to both the regulator and the different DSOs to evaluate how well the NPAM calculates the performance i.e. the customer values.

This paper aims to take a first step in this process by investigating the issue of system reliability. More specifically, the paper addresses the question of how system redundancy is created for the reference networks and compares it with a general reliability model for electrical distribution systems, using the reliability assessment tool RADPOW, developed at $\mathrm{KTH}$ [5],[6].

\section{NETWORK PERFORMANCE ASSESSMENT MODEL NPAM}

\section{A. Background to NPAM}

In 1996 the Swedish electricity market was re-regulated and a new regulating authority STEM was established. The reregulation meant that trading with electricity was exposed to competition and that the net service henceforth constituted a monopoly, with responsibilities as well as privileges. For a DSO this meant being responsible for all electric distribution 
in a geographically well-defined area, offering all customers a connection and setting network tariffs that included a reasonable profit.

Following the re-regulation, the network tariffs for electricity supply in Sweden increased. Despite several attempts by STEM to keep the network tariffs down, for instance, through price freezing, no solution was found. There was therefore an urgent need to find another or a new regulation paradigm.

In 1998, one of the authors of this article [1] was commissioned by STEM to propose a new regulation model for the DSO. The model was to be based on self-regulation and was to give incentives to increase cost-efficiency in the electrical distribution systems. Moreover, the model should be accepted by the customers and different DSOs. Finally, there should be full insight into the model.

The first approach was to use one of the existing models and adapt it to Swedish conditions. However, when no suitable model was found, it was decided to develop a new model. The primary drawback of the existing models was that they were based on the actual electrical distribution systems, and that they did not take into account the efficiency of these networks [1].

The proposed regulation model, i.e. NPAM, meant a change in perspective from a company to a consumer focus, with performance-based regulation. From the consumer perspective, the cost is based on the value to the consumer, in contrast to the cost for the DSO. As a result of this new customer perspective, the legislation had to be changed [7].

\section{B. Overall description of the NPAM}

\section{1) Customer values}

The fundamental starting point of the NPAM is much the same as if it were active in a competitive market. The goal is to calculate the customer values produced by the DSO and sold to the customers. The DSO will be allowed - within the monopoly framework - to be paid for these customer values. The customer values are based on average costs. Moreover, these costs are based on the estimated cost for an electrical distribution system that would be built today with known technology, e.g. it is assumed that underground cables are used rather than overhead lines.

The customer values are separated into a value chain, as illustrated in Fig. 1. The connection is the subscription at a distinct location with power supply required at all times. The connection reliability is the measured reliability at the connection point. The delivery is the actual delivery of energy, i.e., excluding losses. The grid administration is the value created for the customer through the delivery of energy, for instance, or fair measurement of energy, and by charging for the connection and supply. The sum of the customer values is referred to as the Network Performance Assessment (NPA). This value is then compared with the payment from the customers.

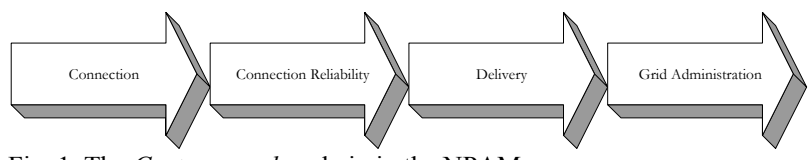

Fig. 1. The Customer value chain in the NPAM

\section{2) Objective prerequisites}

The objective prerequisites are based on pretreatments of the Swedish law [1], and summarize conditions "all circumstances that can not be influenced" for a DSO within their concession area. There are four objective prerequisites for a node as follows: geographical position, maximum load to or from a node, the time distribution of the load, and the nominal voltage level required.

Customers have different requirements according to their location and capacity demand. On one hand, urban customers could be easy to connect, since many customers can share the same cable. On the other hand, connecting rural customers might require long cables that cannot be shared with other customers. Moreover, the power demand differs and is variable throughout the day. The conditions for customers are consequently different and therefore also different for the DSOs. This is an important note since all DSOs are obliged to supply the power demanded at an arbitrary location within their concession area.

\section{3) Reference network - radial and with redundancy}

The connection in the customer value chain is assessed through a reference network. The reference network is an artificial network that is created from the objective prerequisites. It was initially created as a pure radial network. The network is then adjusted to a redundant network where redundancy has been extended, based on a balance between investment cost for DSO and reduced outage cost for customers. The approach for defining the redundancy for the reference network follows in a subsequent chapter.

It is important to distinguish between the process of defining the redundant reference network, which is based on reliability assessment, and the use of the result for the NPAM. The results from the reliability assessment are standard cost functions, used to provide a quality increase for the radial reference networks. This implies that the customer value for the redundant reference network corresponds to extra line length that the DSO in turn would be paid for. The amount of extra line length depends on the network level and average density in [feeder meter/customers]. The approach for defining these corresponding lengths is presented in [1] and will not be treated in this paper.

4) Reliability in terms of expected or attained performance The NPAM distinguishes between two different measures for reliability and outage cost. These are the expected reliability, which is the resulting performance for the reference network, and the attained reliability, which is the measured reliability for the real network. If the attained reliability is less than the expected reliability, there will be a reduction in the assessment of customer value. The assessment of the attained reliability and the expected reliability is in close relation to the assessment of redundancy for the reference network.

\section{Result from test of NPAM}

Table 1 shows results from a test of NPAM in 2002 on 114 companies and 2.7 million customers. (Compare with the total number of DSOs in Sweden of 259 with approx 5.3 million customers.) Results are shown for each customer value, and the total sum of values, i.e. NPA, is compared with the revenue, i.e. what the customers have paid. The final result 
indicates a $19 \%$ overcharge, i.e. a debiting rate of 1.19 . This is of course a conservative result and has been the topic of much discussion. In general, a debiting rate over 1 implies that customers are overcharged for the service provided.

TABLE 1

RESULTS FROM TEST OF THE NPAM

\begin{tabular}{|l|l|l|}
\hline Customer values & $\begin{array}{l}\text { Result per } \\
\text { customer }\end{array}$ & $\begin{array}{c}\text { \% of } \\
\text { NPA }\end{array}$ \\
\hline Connection radial Reference network & SEK 1,297 & $46 \%$ \\
\hline Connection redundancy & SEK 336 & $12 \%$ \\
\hline Reliability & SEK -129 & $-5 \%$ \\
\hline Delivery & SEK 170 & $6 \%$ \\
\hline Administration & SEK 341 & $12 \%$ \\
\hline Services from superior grid & SEK 826 & $29 \%$ \\
\hline Total customer values (NPA)* & SEK 2,841 & $100 \%$ \\
\hline Revenue & SEK 3,389 & $119 \%$ \\
\hline Debiting rate $=$ Revenue/NPA & $\mathbf{1 . 1 9}$ & $\mathbf{1 9 \%}$ \\
\hline
\end{tabular}

*10 SEK 1 Euros.

\section{RELIABILITY ASSESSMENT TECHNIQUES AND REDUNDANCY}

\section{A. Redundancy to improve system reliability}

All technical systems are exposed to randomly occurring failure events. For a system composed of components, this implies that the individual components have a probability of failure, resulting in the total system reliability.

The level of system reliability could be changed in different ways. Technically, changes could be made in either the system or the components. Examples of changes in the system are: keeping the system as simple as possible or using redundancy. Moreover, the redundancy could be either active or in standby [8]. Active redundancy means that all components are in operation. Standby redundancy means that after a component has failed, the redundant component is brought into operation. Examples of changes in the component are: increasing the reliability of the components, or maintaining different types, including correcting or preventing failures. The reliability analysis included in this paper focuses on the first group of principles that involves system improvements by active component redundancy.

Examples of active component redundancy for an electrical distribution system are: transformers or lines in parallel. Standby redundancy is exemplified by a normally open path that would be closed when the normal feeding path has failed, i.e. a meshed system.

The amount of redundancy that is built into an electrical distribution system is formulated in different practice and technical standards. However, ultimately it should be the customer's willingness to pay that defines the extension of redundancy. In other words, the redundancy level should be increased as long as the cost of increasing the level of redundancy is less than the gain by lowering the estimated outage cost for an interruption. However, this is a complicated task: it involves finding the optimal point for system redundancy.

\section{B. Analytical tool for reliability assessment RADPOW}

To evaluate the customer value of system redundancy, the focus of this paper, reliability assessment tools are needed. These tools can relate the impact of component reliability to the system reliability that in turn defines the customer value at different load points.

For this study, a computer program RADPOW (Reliability Assessment of Distribution POWer systems) is used for the reliability analysis. RADPOW was developed by the Centre of Excellence in Electrical Engineering at KTH [5], [6]. The tool includes an analytical approach to the reliability predictions. The mathematical model is based on the generally known techniques of network modeling and the minimal cut set (loadpoint-driven) approach.

There are four types of input data to RADPOW: network topology data, customer and power data, component reliability data and load flow data.

There are two main types of output data from:

1. Load point indices i.e. measures of reliability at each load point (load-point indices) including:

- failure rate [interruptions/year] $=[\mathrm{int} . / \mathrm{yr}]$,

- $\quad$ average outage duration $[$ hours $]=[\mathrm{h}]$,

- annual expected outage time (unavailability) [h/yr], and

- $\quad$ expected energy not supplied [kWh/yr]

2. System indices i.e. measures of reliability for the overall system, including:

- SAIFI [expected number of interruptions/yr, customer],

- $\quad$ SAIDI [average outage duration per customer, $\mathrm{h} / \mathrm{yr}$, customer],

- CAIDI [average total outage duration, $\mathrm{h} /$ interruption], and

- EENS [expected energy not supplied, kWh/yr, customer].

The main feature of RADPOW is that it includes the ability to analyze general distribution systems (including meshed systems), to maintain the network structure in the analysis, to allow implementation in the object-oriented language $\mathrm{C}++$, and to allow the representation of different functions as separate modules.

\section{CALCULATION OF REDUNDANCY IN REFERENCE NETWORK}

\section{A. Outage cost and annual investment cost}

The outage cost has an essential function in the NPAM. It shows how well the DSO has fulfilled the customer expectations. The starting point for the model is on one hand, the customers' readiness to pay for redundancy in the network and on the other hand, an estimation of how well the DSOs have been able to live up to the customers' demand for low outage costs. The fundamental approach is that redundancy should be extended as long as the customers are willing to pay for this.

\section{B. Calculation of redundancy for the reference system}

In the NPAM, the valued outage cost for a pure radial network is expressed as the annual network cost $\left(\mathrm{a}_{\text {annual }}\right)$ and the expected outage cost $\left(\mathrm{a}_{\text {outage }}\right)$. In Fig. 2, this cost is shown as point A. 
I

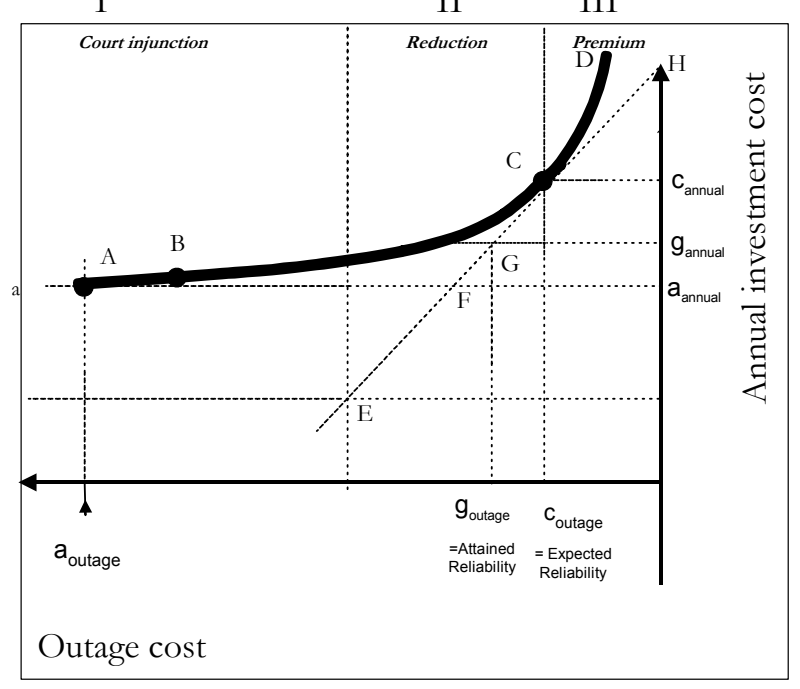

Fig. 2. Outage cost versus annual network costs.

In the next step, the radial grid is considered with respect to finding the best motivated redundancy. The resulting redundant network, will give an increase in annual network cost as well as a decrease in expected outage cost. Fig. 2 illustrates this action as a move from point $\mathrm{A}$ to point $\mathrm{B}$. If all profitable redundancy alternatives are gradually introduced into the network in order of preference for profitability, the relation between the annual network cost and the expected outage cost gradually changes from point $\mathrm{B}$ to point $\mathrm{C}$ in the figure. Every profitable measure put into practice has a lower annual cost for the network owner than the value of the decreasing outage cost for the customer. In a network with low reliability, inexpensive measures (low additional annual cost) have great influence on expected outage cost. The higher the reliability it achieves in the network, the lower the profitability for additional redundancy. The least profitable of the redundancy alternatives are those that have the same annual cost as the resulting decrease in outage cost. These are the measures found close to point $\mathrm{C}$ in the figure. Point $\mathrm{C}$ is the point where the network can perform expected reliability $\left(c_{\text {outage }}\right)$. Ideally, every company should have a network that performs expected reliability. Consequently, point $\mathrm{C}$ is referred to as the solution with optimal redundancy in the network.

To the right of point $\mathrm{C}$ in the figure, no further measures for improved reliability for the network should be taken. Such measures have a higher annual cost than the value of the improved reliability and cannot be motivated and are unlikely to be accepted by the customers.

The line between point $\mathrm{A}$ and point $\mathrm{C}$ in the figure represents the redundant network calculated by the model. This reduction occurs along the line E-F-G-C. The slope of this function is 45 degrees at point $\mathrm{C}$ for expected reliability because there the costs for improving the reliability ( $\left.\mathrm{c}_{\text {annual }}\right)$ and the customers' outage assessment $\left(\mathrm{c}_{\text {outage }}\right)$ of improved reliability coincide.

The relation between increased annual costs in a network and decreased outage cost is a matter of principle for all networks. The difference between different networks is the radial network's own inherent reliability function. This also leads to a variation in the extent of redundancy adjustment with respect to the grid density as well as the number of grid levels in different networks. This, in turn, results in a variation in the expected outage cost between different networks with respect to the density.

\section{Implication of the cost model and its stages}

From Fig. 2 it is possible to conduct a discussion about what should be valid in the different stages of I-III. Point $\mathrm{C}$ expresses the optimal solution where the company has built its redundant network according to the customer value and runs the network such that the customer receives the required reliability i.e. the expected reliability equals the required reliability. However, to the left of point $\mathrm{C}$ i.e. in stage $I I$, the companies that fail to deliver expected reliability are given a reduction based on the achieved customer value compared with expected reliability. At point $G$ this reduction is defined by $\mathrm{g}_{\text {outage }}-\mathrm{C}_{\text {outage., }}$, in accordance with Fig. 2 . The resulting annual investment cost in point $\mathrm{G}$ is consequently given by $\mathrm{g}_{\text {annaual }}=\mathrm{c}_{\text {annual }}-\left(\mathrm{g}_{\text {outage }}-\mathrm{c}_{\text {outage }}\right)$. The reduction may be so large that the DSO receives no compensation for its redundancy, i.e. when point $F$ is reached and the annual investment cost for a pure radial system is reached $\left(\mathrm{a}_{\text {annaual }}\right)$.

If the attained reliability is even lower than at point $\mathrm{F}$, i.e. in stage $I$, the reductions continue down along the line F-E. At some point, a condition occurs in which the reduction could not be considered as linear, and continuous reductions to the same extent would clearly be unreasonable. If it has not happened before it will happen when the deduction equals the network performance assessment value from the radial network, i.e. when the NPA $=0$. Continuous deductions would lead to the DSO being in debt to the customer. Then we are far outside the model's regulation area. In stage $I$ we are outside the model's regulation limit and other actions than reductions must be considered. In stage III it is not obvious what should be done. Even a reliability that is higher than the required reliability i.e. the expected reliability is of value to the customer. The customers will benefit from this improved reliability; however, the marginal improvement is less than the cost to produce it. So far the Swedish regulator will give no premium to DSO with a reliability exceeding the expected reliability. It could, however, be argued that the customers have benefits from the extra reliability, and are willing to pay for this along the line $\mathrm{C}-\mathrm{H}$.

\section{Approach to obtaining the redundant reference network}

The reference network in NPAM has been defined using probabilistic methods. The generally known function, Weibull distribution, has been used for modeling failure occurrences for components in the system. Components are in one of three states: in operation, in service or in failure. Sequential Monte Carlo simulation has been used to model the expected behavior of the system. The reference network for the NPAM has been calculated in five steps as follows:

1. The attained reliability, ( $\left.\mathrm{g}_{\text {outage }}\right)$, is calculated from reported outage statistics for the DSO and their total number of customers.

2. Based on input data to NPAM, a fictive radial network is created. A Monte Carlo simulation is performed for the radial system, including the effect of failure occurrences 
and planned maintenance for feeders, and the resulting outage cost is evaluated, i.e. $a_{\text {outage }}$.

3. Different alternatives for redundancy are investigated for the radial network and the feeder lengths. Those redundancy alternatives that could be estimated to be beneficial are studied further. For each of these alternatives the resulting outage cost is evaluated from simulation studies. From a resulting list of possible redundancy solutions, the first one, profitability, is selected, i.e. where the gain in outage costs is higher than the required annual cost for investment in redundancy.

4. The radial network is simulated including failure occurrences for transformers, and possible solutions for redundancy of transformers. The resulting outage cost is compared with the required annual investment cost.

5. Simulation is performed for the resulting redundant reference network system including possible redundancy for feeders and transformers. The resulting expected reliability is calculated $\left(\mathrm{c}_{\text {outage }}\right)$.

\section{TEST SYSTEM AND RESULTS FROM NPAM AND RADPOW}

This section shows selected results from analysis of a test system both with NPAM and with RADPOW. Note that the analysis for the reference network relates to input data to the NPAM. The main purpose is to illustrate the approaches and the implications of redundant reference network.

\section{A. The Test system and the redundant reference network}

A fictive network has been identified at the $10 \mathrm{kV}$ and $0.4 \mathrm{kV}$ level, which corresponds to the network level 1 and level 2 in the NPAM. Table 2 presents input data for the Test system to the NPAM. The $10 \mathrm{kV}$ network is supplied from one feeding point and is connected to three $0.4 \mathrm{kV}$ networks.

A redundant reference network was identified from simulations following the previously presented approach. Fig. 3 illustrates the resulting reference network for the Test system. Note that this system has one redundancy for the 10 $\mathrm{kV}$ feeder between point $c 5$ and $c 7$. The redundant feeder corresponds to an extra length of $48 \%$ at the $10 \mathrm{kV}$ level. In NPAM the corresponding need for redundancy is presented per customer density. Table 2 gives a system average customer density for the Test system of 8 meters/customer. This density at $10 \mathrm{kV}$ level, i.e. level 2 , result in $20 \%$ extra feeder length according with [1].

\section{B. Results from the NPAM for the Test system}

Table 3 shows results from the NPAM and calculation of outage costs and annual investments at the different points AC. Since this system has only one redundant component, $B=C$. $\mathrm{C}$ represents the redundant system with the two feeders between $\mathrm{c} 5$ and $\mathrm{c} 7$. The table also includes results from the same study of NPAM that was presented in Table 1.

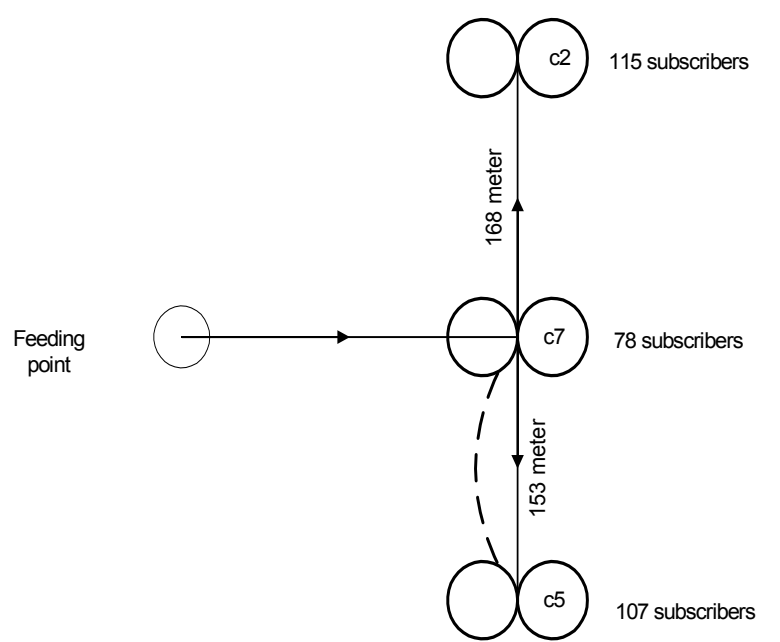

Fig. 3. Reference network for the Test system with resulting redundancy for the feeder $\mathrm{c} 7$ and $\mathrm{c} 5$

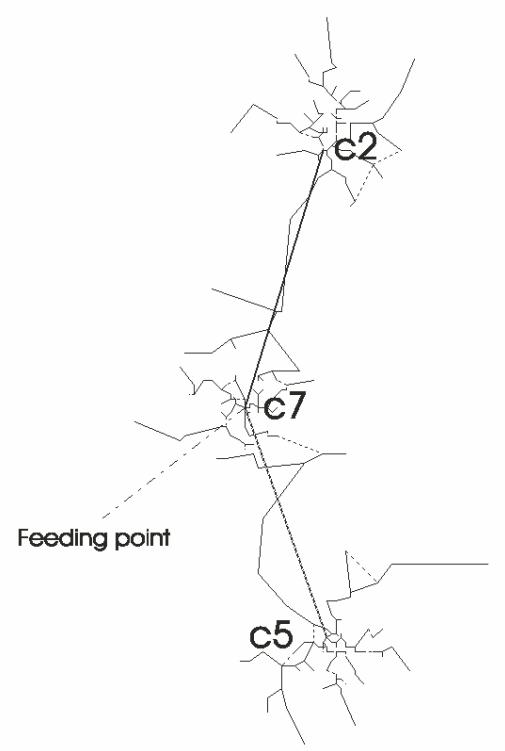

Fig. 4. Network at $0.4 \mathrm{kV}$ and $10 \mathrm{kV}$ level in NPAM for the Test system.

TABLE 2

INPUT DATA FOR THE TEST SYSTEM TO THE NPAM

\begin{tabular}{|l|l|l|l|}
\hline $\begin{array}{l}\text { Corresponding Load } \\
\text { point number in } \\
\text { RADPOW }\end{array}$ & Lp 1 & Lp2 & Lp3 \\
\hline $\begin{array}{l}\text { Transformer } \\
\text { identification }\end{array}$ & $\mathrm{c} 2$ & $\mathrm{c} 5$ & $\mathrm{C} 7$ \\
\hline Transformer power & $889 \mathrm{kVA}$ & $886 \mathrm{kVA}$ & $715 \mathrm{kVA}$ \\
\hline Transformer current & $50,4 \mathrm{~A}$ & $50,2 \mathrm{~A}$ & $40,5 \mathrm{~A}$ \\
\hline Nominal voltage & $10,797 \mathrm{kV}$ & $10,798 \mathrm{kV}$ & $10,800 \mathrm{kV}$ \\
\hline Annual Energy & $3,31 \mathrm{MWh}$ & $3,29 \mathrm{MWh}$ & $2,54 \mathrm{MWh}$ \\
\hline $\begin{array}{l}\text { No of 0,4 kV } \\
\text { subscribers }\end{array}$ & 115 & 107 & 78 \\
\hline Line length 10 kV & 168 & 153 & 0 \\
\hline $\begin{array}{l}\text { Total line length in } \\
\text { the local grid }\end{array}$ & $919 \mathrm{~m}$ & $863 \mathrm{~m}$ & $379 \mathrm{~m}$ \\
\hline $\begin{array}{l}\text { Average density } \\
\text { (meters/subscriber) }\end{array}$ & 9.5 & 9.5 & 4.9 \\
\hline
\end{tabular}


TABLE 3

RESULTS FROM THE NPMA

\begin{tabular}{|l|l|l|}
\hline \multirow{2}{*}{$\begin{array}{l}\text { Cost } \\
{[\text { öre*/kWh }]}\end{array}$} & \multicolumn{1}{|c|}{ System } & \multicolumn{1}{|c|}{ Fest system } \\
\hline $\mathrm{a}_{\text {outage }}$ & $\begin{array}{l}0.93 \\
(0.4 \mathrm{kV}: 0.67 \text { and } 10 \mathrm{kV}: 0.26)\end{array}$ & 5.48 \\
\hline $\mathrm{a}_{\text {annual }}$ & $\begin{array}{l}3.91 \\
(0.4 \mathrm{kV}: 2.04 \text { and } 10 \mathrm{kV}: 1.87)\end{array}$ & 6.89 \\
\hline $\mathrm{g}_{\text {outage }}$ & 0.30 & 1.67 \\
\hline $\mathrm{g}_{\text {annual }} * *$ & 4.09 & 7.63 \\
\hline $\mathrm{c}_{\text {outage }}$ & $\begin{array}{l}0.13 \\
(0.4 \mathrm{kV}: 0.05 \text { and } 10 \mathrm{kV}: 0.08)\end{array}$ & 0.62 \\
\hline $\mathrm{c}_{\text {annual }}$ & $\begin{array}{l}4.26 \\
(0.4 \mathrm{kV}: 2.26 \text { and } 10 \mathrm{kV}: 2.00)\end{array}$ & 8.68 \\
$* 100$ öre $=1$ SEK and $10 \mathrm{SEK} \sim$ approximately 1 Euros. \\
$* * \mathrm{c}_{\text {annual }}-\left(\mathrm{g}_{\text {outage }}-\mathrm{c}_{\text {outage }}\right)$
\end{tabular}

C. Modeling of the Test system for assessment with RADPOW

1) Input data and network reliability model to RADPOW

Each $10 \mathrm{kV}$ feeder in the Test system has around 100 subscribers at $0.4 \mathrm{kV}$ level. Fig 5. shows a network model for the Test system including eight component types: $10 \mathrm{kV}$ lines, $0.4 \mathrm{kV}$ lines, and transformers. It is assumed that the system has a perfect protection system including breakers and transformers with zero probability of failure.

The Test system is modeled with three load points, which have around 100 subscribers at the $0.4 \mathrm{kV}$ level and components $c 3, c 6$ and $c 8$ represent each a $0.4 \mathrm{kV}$ network. Consequently, the complete network model with all set of lines at $0.4 \mathrm{kV}$ would result in a very extensive model, although the Test system is a small system. Failure statistics show that it is generally the $10 \mathrm{kV}$ level that contributes most to the load point unavailability [9]. Moreover, the results from the NPAM model for the Test system showed that it was the $10 \mathrm{kV}$ level that contributed most to the customer value, i.e. the voltage level where redundancy could be motivated. Considering these two aspects, and the fact that the purpose of this study is illustrative rather than to calculate reliability for a specific system, it was decided to include failures only at the $10 \mathrm{kV}$ level.

Fig 5. shows the resulting reliability model that was used for the reliability assessment with RADPOW. The reliability model includes two $10 \mathrm{kV}$ lines $\mathrm{c} 1$ and $\mathrm{c} 4$. Consequently, there are three alternatives, as shown in the figure, to create redundancy:

1. parallel component for $\mathrm{c}^{(}\left(\mathrm{cl}^{\prime}\right)$

2. parallel component for $\mathrm{c} 4(\mathrm{c} 4$ ')

3. coupling between Lp1 and Lp2 (c14')

Table 4 presents the input data used for the three different sets of components in the model. All data is from [4].

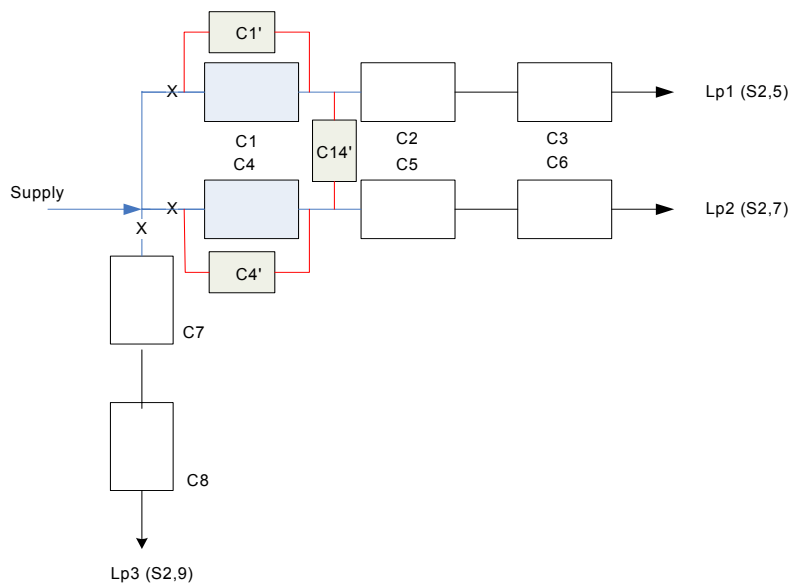

Fig. 5. Network model for the Test system for assessment with RADPOW

TABLE 4

COMPONENT RELIABILITY INPUT DATA FOR THE TEST SYSTEM TO RADPOW

\begin{tabular}{|c|c|c|c|}
\hline \multicolumn{2}{|c|}{ Component of type line $10 \mathrm{kV}$} & \multirow{2}{*}{$\begin{array}{l}\text { Failure rate** } \\
\text { [int./yr] }\end{array}$} & \multirow{2}{*}{$\begin{array}{l}\text { Duration*** } \\
\text { [hours] }\end{array}$} \\
\hline No & Length & & \\
\hline $\mathrm{cl}, \mathrm{cl}{ }^{\prime}$ & $168 \mathrm{~m}$ & 0.0226 & 3.2833 \\
\hline $\mathrm{c} 4, \mathrm{c} 4{ }^{\prime}$ & $153 \mathrm{~m}$ & 0.0205 & 3.2833 \\
\hline c14’ & $\mathrm{c} 1+\mathrm{c} 4 *=321 \mathrm{~m}$ & 0.0431 & 3.8333 \\
\hline
\end{tabular}

*approximation since the actual length is unknown

**from mean time to failure of 218.95 years for an average line of 34 meter i.e. 0.000134 interruptions/year, meter from NPAM [4].

*** from mean down time and input data to NNM of 197hours for lines and 13800 seconds [4].

\section{Result from reliability assessment with $R A D P O W$}

Table 5 summarizes the result from reliability assessment with RADPOW for the Test system and the base case with a radial distribution system. The result shows on the reliability characteristic of the analyzed system. However, for a comparison with results from the NPAM, these results need to be translated into economic terms, which will be considered in the next section.

TABLE 5

RESULTS* FROM RELIABILITY ASSESSMENT WITH RADPOW FOR THE TEST

SYSTEM AND RELIABILITY MODEL FOR THE 10KV COMPONENTS
\begin{tabular}{|l|l|l|l|}
\hline $\begin{array}{l}\text { Load } \\
\text { point }\end{array}$ & $\begin{array}{l}\text { Failure rate } \\
{[\text { int./yr }]}\end{array}$ & $\begin{array}{l}\text { Duration } \\
{[\text { hours }]}\end{array}$ & $\begin{array}{l}\text { Unavailability } \\
{[\text { hours/yr }]}\end{array}$ \\
\hline Lp1 & 0.0226 & 3.28 & 0.0741 \\
\hline Lp2 & 0.0205 & 3.28 & 0.0675 \\
\hline Lp3 & 0.000 & - & 0.000 \\
\hline \multicolumn{4}{|c|}{ System index $*$} \\
\hline SAIFI $=0.01598$ & SAIDI $=0.05247$ \\
\hline CAIDI $=3.2833$ & ASAI $=0.999994$ \\
\hline
\end{tabular}

*Only including failures for $10 \mathrm{kV}$ lines.

E. Economic assessment for the Test system based on results from reliability assessment with RADPOW

1) Outage Cost

The outage cost has been evaluated in similar way to that in the NPAM. The outage cost in the NPAM depends on the average density, i.e. meter/subscriber. Figure 13, in [1] shows the values used for the NPAM (based on customer interruption cost from Swedish utilities, included in the Cigré report [9]). Moreover, the cost is separated into non-announced or announced outages, and is given in the form: $\mathrm{x} S E K / \mathrm{kW}$ and $\mathrm{y}$ 
SEK / $\mathrm{kWh}$. This study has only considered the non announced outages: those that occur randomly.

The outage cost is calculated with mean values of system specific data as follows:

outage $\cos t=\left(\begin{array}{l}x \cdot \text { supplied energy } \cdot(\text { SAIFI / 8760) }+ \\ y \cdot \text { SAIDI } \cdot(\text { supplied energy/8760) }\end{array}\right)$

where $\mathrm{x} \mathrm{kr} / \mathrm{kW}$ and $\mathrm{y} \mathrm{kr} / \mathrm{kWh}$, and supplied energy is the total served energy per year.

The outage cost for the Test system can be calculated as follows. From Table 2 it is given that the Test system has: supplied energy of $9140000 \mathrm{kWh}$, and that the average density is 8 meter/subscriber. This density gives from Figure 13 , in [1], that $\mathrm{x}=22 \mathrm{kr} / \mathrm{kW}$ and $\mathrm{y}=110 \mathrm{kr} / \mathrm{kWh}$. The system index is calculated with RADPOW. Input in (1) gives that the outage cost is approximately $=23000 *($ SAIFI $+5 *$ SAIDI). For the base case system, i.e. the radial system, the resulting outage cost, in [SEK/år], can then be calculated as follows: $23000 \cdot(0.01598+5 \cdot 0.05247) \approx 6402 S E K / y r$.

\section{2) Summary of proposed approach}

The approach aims to investigate the possible economic benefit of introducing different redundancy alternatives for the system. A comparative figure is defined as follows:

$$
\text { comparative figure }=\frac{m \arg \text { inal benefit }}{m \text { arg inal } \cos t}
$$

where Marginal benefit $=$ reduced outage cost due to activity per year and Marginal cost = yearly cost to apply the activity.

Those alternatives that have a comparative figure $>1$ are defined as economically beneficial.

The approach to identifying the optimal distribution system is as follows:

1. Calculate the system interruption cost i.e. expected outage cost. The first time this step is entered, the base case is evaluated, i.e. the radial distribution system $\left(\mathrm{a}_{\text {outage }}\right)$.

2. Test different possible activities for system redundancy for the system.

3. Investigate if there are one or more of the activities from Step 2 that result in a comparative figure $>1$.

- if NO then it is not beneficial to improve the system redundancy GOTO Step 5.

- if YES apply the activity with highest comparative figure. The outage cost for the system $=$ outage cost for the system after this activity has been introduced, i.e. the new system. The first time this step is entered $\left(b_{\text {outage }}\right)$ is evaluated.

4. Repeat the analysis for the new system GOTO Step 1.

5. The outage cost for the resulting system equals the expected outage cost $\left(\mathrm{c}_{\text {outage }}\right)$.

\section{3) Application of approach for the Test system}

Table 6 summarizes the results when calculating the effect of introducing different alternative redundancy alternatives, i.e., the result after Step 3 in the approach.

The alternatives that have been studied imply the introduction of further feeder length. Consequently, the marginal cost can be calculated from the cost of introducing 1 meter feeder per year. For the following studies this cost has been assumed to be $19.5 \mathrm{SEK} /$ meter.

An example of the calculation procedure is presented for alternative $\mathrm{c}^{\prime}$ '. Component $\mathrm{c} 1$ is a $10 \mathrm{kV}$ feeder of $168 \mathrm{~m}$ supplying Load point 1 . This alternative implies that a redundant component is introduced with the same characteristic as $\mathrm{c} 1$. A reliability model for this new system is implemented in RADPOW. From a reliability assessment with RADPOW, the resulting system index for the new system gives the output of SAIFI $=0.02407$ and SAIDI $=0.00733$. From (1) the resulting outage cost can be calculated as 2937 SEK/yr. The marginal benefit is given by: $6402-2937=3$ $465 \mathrm{SEK} / \mathrm{yr}$, the marginal cost $=19.5 * 168=3275 \mathrm{SEK} / \mathrm{yr}$, and the resulting comparative figure is given by $=3465 / 3275=$ 1.058 .

TABLE 6

RESULTS FROM ANALYZING DIFFERENT ALTERNATIVES FOR REDUNDANCY FOR THE TEST SYSTEM AND 10KV LEVEL WITH USE OF RADPOW

\begin{tabular}{|l|l|l|l|l|}
\hline Alt. & $\begin{array}{l}\text { Outage cost } \\
{[\text { SEK/yr }]}\end{array}$ & $\begin{array}{l}\text { Marginal } \\
\text { benefit } \\
{[\text { SEK/yr }]}\end{array}$ & $\begin{array}{l}\text { Marginal } \\
\text { cost } \\
{[\text { SEK/yr }]}\end{array}$ & $\begin{array}{l}\text { Comparative } \\
\text { figure }\end{array}$ \\
\hline C1 $^{\prime}$ & 2937 & 3465 & 3275 & 1.058 \\
\hline C4 $^{\prime}$ & 3457 & 2945 & 3152 & 0.9873 \\
\hline C14' $^{\prime}$ & $\sim 0$ & 6402 & 6260 & 1.023 \\
\hline
\end{tabular}

The comparative figures presented in Table 6 can be used to rank the alternative solutions for system redundancy as follows:

$\mathrm{c}^{\prime}=1.058$

$\mathrm{c}^{\prime} 4^{\prime}=1.023$

$\mathrm{c}^{\prime}{ }^{\prime}=0.9873$

The conclusion is that c1' and c14' are beneficial redundancy improvements in the Test system. The solution is that redundancy should be included for the $10 \mathrm{Kv}$ line, c1, with resulting outage cost of $2937 \mathrm{SEK} / \mathrm{yr}\left(\mathrm{b}_{\text {outage }}\right)$. The redundant feeder corresponds to an extra length of $78 \%$ at the $10 \mathrm{kV}$ level. The next step is to evaluate if there are any beneficial redundancy alternatives for the new system, i.e. Step 4 in the approach.

\section{4) Other possible redundancy alternatives}

Other possible alternatives for system redundancy would be introducing redundancy for transformers, or supplying from other distribution systems from a normally open point.

The alternative of introducing a redundant transformer has been studied. Component $\mathrm{c} 2$ was selected since it supplies the largest number of customers compared with the other transformer, i.e. c5 and c7. The result showed that the marginal benefit is not comparable with the investment cost of investing in a new transformer. The conclusion was, therefore, that introducing redundant transformers is not a beneficial alternative for the Test system. It is interesting to note that this result agrees with the result for the NPMA study for the Test system, where it was not efficient to include redundant transformers. The result can also be compared with general results from NPAM where the $0.4 / 10 \mathrm{kV}$ transformers are never redundant, and the $10 / 70 \mathrm{kV}$ and higher transformers voltage are always redundant [1]. 
5) Application for the Test system with redundancy Reliability assessment with RADPOW for the new system gives that: SAIDI $=0.02407$ and SAIFI $=0.00733$. The resulting outage cost is then calculated as: $2937 \mathrm{SEK} / \mathrm{yr}$.

The different alternatives for redundancy are as follows:

1. parallel component for $\mathrm{c} 1\left(\mathrm{c} 1{ }^{\prime}\right)$

2. parallel component for $\mathrm{c} 4$ (c4')

3. coupling between Lp1 and Lp2 (c14')

Alternative 1 has already been incorporated and including further components in parallel would only yield a small improvement but still require the same investment cost. This alternative is consequently not beneficial.

Alternative 2 was not beneficial for the radial Test system, and would therefore not be beneficial for the redundant Test system.

Alternative 3, to include a new line between load point 1 and load point 2 , is analyzed. Results from reliability assessment with RADPOW give that: both system index and outage cost are close to zero. The marginal benefit is then given by: 2937 $\mathrm{SEK} / \mathrm{yr}$, and the marginal cost $=220,6 * 321=$

$6260 \mathrm{SEK} / \mathrm{yr}$, and the resulting comparative figure is given by $=2^{\prime} 937 / 6^{\prime} 260=0.469$.

Consequently, there are no economically beneficial alternatives to extend the redundancy for the Test system than the first activity, i.e. redundancy for line $\mathrm{c} 1$.

In accordance with Step 5 in the approach, the resulting outage cost for the resulting system now equals the expected outage cost $\left(\mathrm{c}_{\text {outage }}\right)=2973 \mathrm{SEK} / \mathrm{yr}$. Observe that for this example the points $c_{\text {outage }}$ and $b_{\text {outage }}$ coincide since there is only one beneficial redundancy activity for the system.

\section{F. Concluding remarks for the analysis of the Test system}

The conclusion from the reliability and cost assessment for the Test system, from both calculation models, is that the optimal component type for redundancy is the $10 \mathrm{kV}$ line, i.e. the solution that gives the right customer value. Moreover, the optimal component for which to include redundancy is: component $\mathrm{c} 4$, from the NPAM analysis, and component $\mathrm{c} 1$ from the RADPOW analysis.

There might be numerous arguments against these models yielding the equivalent numerical result, and also against the NPAM model giving a true picture of a real network. For example, the Monte Carlo simulation methods used for the NPAM model would have large uncertainties in results when analyzing small systems like this. Moreover, the result is very sensitive to the cost parameters employed, as in this example, the cost per line length. Other arguments could be that the reliability model for the NPAM and the RADPOW analysis differs; for instance, in RADPOW each component is represented by its own failure rate and outage time, but in NPAM some functions are built into the system model, like the breaker function. For this simple Test system, however these aspects were not included.

\section{CONCLUSIONS}

This paper has illustrated the role played by the NPAM with respect to identifying a redundant reference network. Moreover, this implies identifying the optimal redundancy for the system related to customer value.
The application study for the small Test system and the comparative study using the RADPOW tool, has put light on how the redundant reference networks are created and used for the NPAM. Although no general conclusions can be drawn from the numerical results due to the simplicity of the test system and the differences in reliability models - they demonstrate the reliability assessment theory behind NPAM which it in it self is a significant contribution. For future studies it would be of great interest to expand the test system into a real distribution system for further investigations evaluating the NPAM.

\section{REFERENCES}

[1] Larsson, M. B-O, "The Network Performance Assessment Model - A new framework of regulating the Electricity Network Companies", Licentiate Thesis KTH, Department of Electrical Engineering, TRITAICS-0501, 2005.

[2] Larsson, M. B-O, "The Network Performance Assessment Model Regulation with a Reference Network", Proceedings of Market Design Stockholm, 2003.

[3] Gammelgård M. and Larsson M. B-O., "The challenge of regulating natural monopolies in electrical distribution, experiences from Sweden", Proceedings of CIRED 2003.

[4] Larsson, M. B-O,'The Network Perfomance Assessment Model from the Inside", (in Swedish), Åhus, Sweden, (www.stem.se), 2004.

[5] Bertling, L, "Reliability Centred Maintenance for Electric Power Distribution Systems", Doctoral Thesis KTH, Department of Electrical Engineering, Stockholm, ISBN 91-7283-345-9, TRITA-ETS-2002-01, ISSN 1650-674X, 2002.

[6] Bertling, L, "RADPOW status report", Internal report, KTH, Department of Electrical Engineering, Stockholm, A-EES-0008, 2000.

[7] Government proposition, "Proposition 2001/02:56: Energimarknader i utveckling - bättre regler och tillsyn" Riksdagens tryckeriexpedition, (in Swedish), Stockholm, Sweden, 2001.

[8] Kuo W., Prasad, V. R., Tillman F. A., Hwang C-L, "Optimal reliability design - fundamentals and applications", Cambridge university press, 2001, ISBN 0521781272.

[9] Cigré Task Force 38-06-01, Methods to Consider Customer Interruption Costs in Power System Analysis, Paris, 2001.

[10] Bertling, L., Eriksson, R., Allan, R.N., Gustafsson, L.Å. and Åhlén M., "Survey of Causes of Failures Based on Statistics and Practice for Improvements of Preventive Maintenance Plans", 14th PSCC Sevilla, June 2002.

\section{BIOGRAPHIES}

Lina Bertling (S'98-M'02) received the Ph.D., and Tech. Lic. degree in electric power systems in 2002 respectively 1999, from the Department of Electrical Engineering and the M.Sc. degree in Systems engineering in 1997, all from the Royal Institute of Technology (KTH), Stockholm, Sweden. She is currently engaged at KTH as Research Associate and Project Leader of the research program on Asset management in power systems. Her research interests are in reliability assessment of power systems, component reliability modelling and reliability centered maintenance methods.

Mats B-O Larsson received the Tech. Lic. degree in electric power systems in 2005, from the Department of Electrical Engineering and the M.Sc. degree in Engineering Physics in 1980, both from the KTH, Stockholm, Sweden.

Carl Johan Wallnerström is a Master student the Department of Electrical Engineering at KTH. He is currently doing his Master thesis project with the research group on Asset management in power systems. 